A R T I G O

\title{
ALBERTO PASQUALINI E GETÚLIO VARGAS: REVISITANDO INTERPRETAÇÕES
}

Alberto Pasqualini and Getúlio Vargas: reexamining interpretations

Alberto Pasqualini y Getúlio Vargas: revisitando interpretaciones

DOI: http://doi.org/10.1590/\$2178-14942020000300007

Universidade Federal do Rio Grande do Sul - Porto Alegre (RS), Brasil.

*Doutor em História pela Universidade Federal do Rio Grande do Sul (douglasangeli@hotmail.com).

(D) http://orcid.org/0000-0001-6540-9358

Artigo recebido em 27 de abril de 2020 e aprovado para publicação em 13 de julho de 2020. 


\title{
RESUMO
}

0 objeto deste artigo se centra nas relações políticas entre Alberto Pasqualini e Getúlio Vargas, com o objetivo de rediscutir interpretações relativas ao Partido Trabalhista Brasileiro baseadas na dicotomia existente entre a ala doutrinária e a ala pragmática, então personificadas nas figuras de Pasqualini e Vargas. Com base no cruzamento e na análise de fontes primárias (correspondências e jornais), o presente artigo percorre o histórico de aproximações e afastamentos entre ambos. A análise inicia-se nos anos precedentes ao Estado Novo e passa a examinar a atuação de Pasqualini na candidatura de Vargas às eleições de 1950, com vistas a superar a chave explicativa que resumia sua atuação ao papel de doutrinador, em oposição ao pragmatismo político de Vargas.

PALAVRAS-CHAVE: Alberto Pasqualini; Getúlio Vargas; Partido Trabalhista Brasileiro.

\begin{abstract}
The focus of this study is the political relationships between Alberto Pasqualini and Getúlio Vargas, with which I seek to (re)discuss interpretations regarding the Brazilian Labor Party (Partido Trabalhista Brasileiro) based on the dichotomy between the doctrinaire and the pragmatic wings respectively represented by Pasqualini and Vargas. By cross-referencing and analysis of primary sources (such as correspondence and newspapers), this article walks through the history of approximations and distancing between the two individuals. Said analysis starts in the previous years of the New State Order (Estado Novo), to then turn to examine the role played by Pasqualini in the candidacy of Vargas during the 1950's election, seeking to overcome the traditional explanation that reduced his performance to the role of indoctrinator, in opposition to the political pragmatism of Vargas.
\end{abstract}

KEYWORDS: Alberto Pasqualini; Getúlio Vargas; Partido Trabalhista Brasileiro.

\section{RESUMEN}

Son objeto de este artículo las relaciones políticas entre Alberto Pasqualini y Getúlio Vargas, con el objetivo de rediscutir interpretaciones sobre el Partido Laborista Brasileño basadas en la dicotomía entre el ala doctrinaria y el ala pragmática que se personificaban en las figuras de Pasqualini y Vargas. A partir del cruce y análisis de fuentes primarias (correspondencia y periódicos), se desglosa el histórico de aproximaciones y alejamientos entre ambos actores. Dicho análisis se inicia en los años anteriores al Estado Novo, pasando a examinar la actuación que tuvo Pasqualini en la candidatura de Vargas en las elecciones de 1950, con el objetivo de superar la tradicional explicación que reducía dicha actuación al papel del adoctrinador, en contraposición al pragmatismo político de Vargas.

PALABRAS CLAVE: Alberto Pasqualini; Getúlio Vargas; Partido Laborista Brasileño. 


\section{CONSIDERAÇÕES INICIAIS}

Iberto Pasqualini (1901-1960) foi um político natural do Rio Grande do Sul, vereador
em Porto Alegre entre 1936 e 1937, membro do Departamento Administrativo do Estado entre 1939 e 1943, secretário de Interior e Justiça entre 1943 e 1944. Em 1946, ingressou no Partido Trabalhista Brasileiro (PTB), pelo qual foi candidato derrotado ao Governo do Estado em 1947 e em 1954. Em 1950 foi eleito senador, exercendo mandato entre 1951 e 1955, destacando-se como relator do projeto de lei que culminou na criação da Petrobras. Ficou conhecido como o teórico do trabalhismo. Em diferentes momentos, sua trajetória se cruza com a de seu ilustre conterrâneo Getúlio Dornelles Vargas (1882-1954).

Este artigo é resultado da pesquisa de doutorado realizada no Programa de Pós-Graduação em História da Universidade Federal do Rio Grande do Sul, que gerou a tese "O candidato do povo: as campanhas eleitorais de Alberto Pasqualini e a construção do eleitor na experiência democrática (1945-1954)". Para o estudo das três campanhas eleitorais disputadas por Pasqualini no PTB, desfolharam-se diversas camadas de interpretações em que se cruzam a memória política, os estudos realizados no âmbito da ciência política na década de 1980 e a historiografia mais recente sobre o tema. Para compreender a atuação política desse senador gaúcho, deve-se ir além das categorias de teórico, doutrinador, ideólogo. Nesse esforço, foi fundamental refletir sobre as relações entre Pasqualini e Vargas em diferentes momentos, também antes do Estado Novo.

0 objetivo do presente artigo é apresentar uma visão menos dicotômica da atuação de ambos. Na referida tese, realizou-se um esforço de compreender como Alberto Pasqualini se inseria nas práticas políticas de seu tempo, havendo a necessidade de romper com outros rótulos que embasaram as interpretações sobre o trabalhismo, especialmente no Rio Grande do Sul: a dicotomia entre pragmáticos e programáticos, personificada na relação entre Getúlio Vargas e Alberto Pasqualini'. Em torno dos dois protagonistas, grande parte dos estudos anteriores havia consolidado esquemas interpretativos para compreensão do trabalhismo, que serão revistos neste artigo e contrastados com o uso de fontes elementares.

\section{O TEÓRICO DO TRABALHISMO}

$\mathrm{E}$ m sua tese sobre a política no Rio Grande do Sul entre 1930 e 1964, Carlos E. Cortés aborda os papéis exercidos por Loureiro da Silva², José Diogo Brochado da Rocha ${ }^{3}$ e Alberto Pasqualini, todos sob a influência de Getúlio Vargas, na construção do PTB nesse estado. Para Cortés (2007), Pasqualini passou a ser o líder ideológico do PTB, contribuindo com Vargas no papel de "filósofo do partido", algo necessário para a legitimidade doutrinária 
e para diferenciar o partido da "politicagem" do Partido Social Democrático (PSD). 0 autor classifica Pasqualini como um idealista, enquanto Loureiro é tratado como o "organizador" do partido e José Diogo como um político que, diferentemente de Pasqualini, "contribuiu com seu apelo populista" e com "um dom para organizar bases políticas" (Cortés, 2007: 193-194). Essa visão do autor fica sintetizada na seguinte afirmação: "Deixando Loureiro da Silva e José Diogo para organizar o PTB gaúcho e Pasqualini para escrever poemas ideológicos em prosa, Vargas voltou para o Rio de Janeiro para assumir sua cadeira do PSD no Senado" (Cortés, 2007: 194, grifo do autor).

É preciso salientar que, quando Carlos Cortés se refere à atuação de Pasqualini no período anterior ao Estado Novo, concebe-a de maneira distinta da imagem de "filósofo" e "idealista" que constrói sobre a atuação do político no trabalhismo. Cortés (2007: 124) demonstra como Getúlio Vargas se valeu de Pasqualini para sabotar os planos de Oswaldo Aranha - que pretendia reconciliar o governo estadual de Flores da Cunha com 0 governo federal ${ }^{4}$. Para o autor, Alberto Pasqualini e Loureiro da Silva foram os principais defensores de Vargas na luta contra Flores (Cortés, 2007: 191). A maneira de conceber o papel de Pasqualini no PTB, contrastando com a concepção acerca da participação de Loureiro da Silva e de José Diogo no mesmo processo, provavelmente está relacionada à fonte utilizada por Cortés: em grande medida, o autor embasa seus argumentos em entrevistas realizadas com lideranças políticas na segunda metade da década de 1960. Como Vargas havia morrido em 1954, Pasqualini em 1960 e Loureiro em 1964, dos principais envolvidos na construção do PTB no Rio Grande do Sul restava apenas José Diogo, entrevistado pelo autor em 1967. É perceptível, no texto de Cortés, a construção narrativa do entrevistado, marcada pelas dissenções no PTB que culminaram com sua saída do partido após perder a indicação como candidato a governador para Pasqualini, com apoio de Vargas, em 1954.

Miguel Bodea escreveu aquela que, provavelmente, é a obra mais conhecida sobre o trabalhismo no Rio Grande do Sul: Trabalhismo e populismo no Rio Grande do Sul. Com grande impacto nas obras posteriores, o autor esquematizou o surgimento do PTB gaúcho por três vertentes consideradas com base em suas origens distintas:

- A corrente sindicalista, oriunda do queremismo e da ala trabalhista do PSD;

- A corrente doutrinário-pasqualinista, originária da União Social Brasileira sob a liderança de Alberto Pasqualini;

- A corrente pragmático-getulista, formada por políticos oriundos do PSD e que ingressam no PTB sob orientação de Getúlio Vargas (Bodea, 1992: 20-28). 
Quando analisa os diferentes papéis exercidos no trabalhismo por Vargas e Pasqualini, é o de teórico que cabe ao último, e Bodea considera que havia uma divisão de tarefas entre ambos, o que gerava uma "complementaridade conflitiva" em três âmbitos:

- Na estratégia política global, entre o projeto político nacional, que caberia a Vargas, e o projeto de construção do partido, que caberia a Pasqualini;

- Na divisão geográfica, entre a liderança nacional de Vargas e a liderança regional de Pasqualini;

- Na divisão das funções político-partidárias, entre o papel de estrategista político, que caberia a Vargas, e o de doutrinador e teórico, que caberia a Pasqualini (Bodea, 1992: 140, grifo do autor).

Nessa concepção, o projeto trabalhista era ambivalente, pois enquanto tendia a "mobilizar as massas ao nível da sociedade civil" (Bodea, 1992: 186), buscava também uma política de compromisso no âmbito da sociedade política e do Estado. É nessa ambivalência que o autor situa o relacionamento (conflitivo, porém complementar) de Pasqualini e de Vargas: enquanto Pasqualini atuava principalmente na esfera da sociedade civil, privilegiando, portanto, o aspecto da "mobilização das massas", Vargas atuava sobretudo ao nível do aparelho de Estado e da sociedade política, promovendo uma política de alianças e de compromisso entre as classes subalternas e um setor modernizante das elites (Bodea, 1992: 186)5.

Essa divisão de tarefas também é explicada por Bodea (1992: 188) em um "padrão de evolução histórica mais ampla das lideranças gaúchas", em que o autor destaca desde as relações entre Borges de Medeiros e Getúlio Vargas até as relações entre João Goulart e Leonel Brizola. Analisando a forma como Miguel Bodea insere Vargas e Pasqualini em uma tradição que tem origens no positivismo e busca legitimar João Goulart e Leonel Brizola como herdeiros do trabalhismo e dessa tradição, Igor Gastal Grill (2008: 205-206) afirma: "Bodea sustenta a continuidade e a relevância do projeto ao qual é filiado [...]. Ao conceber a 'tradição política' como depositária de uma história regional ímpar e a complementaridade positiva entre 'práxis' e 'formulação teórica' afirma a sua posição nessa genealogia" 6 .

Mesmo em trabalhos recentes, percebe-se a absorção da imagem de teórico do trabalhismo em relação a Pasqualini. Em sua tese de doutorado, Roberto Bitencourt Silva (2012) analisa a trajetória de Alberto Pasqualini considerando-o um intelectual. Para ele, Pasqualini "consiste em expressão de um típico caso da relação estabelecida entre os intelectuais e a política, potencialmente capaz de suscitar uma reflexão pertinente às eventuais influências do pensamento na vida política cotidiana" (Silva, 2012: 24-25). Procurando compreender Alberto Pasqualini como um intelectual e remetendo à obra de Max Weber, o autor destaca como 
uma dimensão importante na relação entre os intelectuais e a política aquela concernente às tensões e aos dilemas de natureza ética: "Tal fenômeno tende geralmente a se manifestar, pois a lógica que orienta a perspectiva e o fazer intelectual é distinta da que impera na orientação do sujeito que exerce um papel político stricto sensu" (Silva, 2012: 78-79, grifo do autor). Isso leva o autor a reforçar a ideia de uma dicotomia entre Vargas e Pasqualini: "As divergências entre os setores alinhados a Pasqualini e a Getúlio foram, sobretudo, de natureza politicamente comportamental. Potencialmente relacionadas aos distintos modus operandi que tendem a caracterizar a atuação política dos intelectuais e dos políticos profissionais" (Silva, 2012: 215, grifo do autor).

0 autor entende Pasqualini como um intelectual que exerceu o papel de ideólogo e de especialista (experto) do trabalhismo: ideólogo por ser produtor e disseminador de uma visão ética, política e social do mundo; especialista por ser formulador de propostas e programas socialmente reformistas (Silva, 2012: 104)7 0 ambiente no qual se deu a atuação de Pasqualini no PTB nas campanhas eleitorais de 1947, 1950 e 1954 possuía, certamente, o conflito entre as éticas da convicção e da responsabilidade, conforme concebido por Max Weber (2011). Pasqualini, porém, não pode ser visto como alguém de um fazer distinto ao da política e que com ela lida, e sim como um político que se formou e atuou em um meio onde quem se dedica à política como vocação sofre pressões éticas e "se compromete com potências diabólicas" (Weber, 2011: 152).

\section{A ObRA DE Alberto PASQUALINI}

Iberto Pasqualini foi formulador de ideias políticas e sociais incorporadas aos programas de
Luas candidaturas pelo PTB. Formado na Faculdade de Direito de Porto Alegre e professor da mesma instituição, Pasqualini detinha um capital intelectual que lhe permitia formular propostas para os problemas de seu tempo, e o fez de maneira bastante original. Conforme Luiz Alberto Grijó (2007: 85), Pasqualini foi reconhecido como um dos poucos membros do PTB que se "dedicaram a elaborar e difundir princípios fundamentados em disciplinas como a Filosofia, História, Sociologia e mesmo a Teologia que sustentassem linhas de ação coerentes para os seus militantes e simpatizantes". 0 autor salienta duas influências básicas em Pasqualini: sua origem relacionada com "o mundo colonial italiano" e com os valores pregados por religiosos católicos na sua formação cultural e escolar, podendo ser considerado um "tradutor dos conteúdos da chamada doutrina social da Igreja para as disputas político-partidárias inauguradas no Brasil depois da queda do Estado Novo" (Grijó, 2007: 91-94).

Os escritos de Alberto Pasqualini formam uma obra bastante fragmentada e dispersa, resultado dos contextos e ambientes institucionais em que foram produzidos, concernentes 
quase todos ao meio político, e não ao meio acadêmico. 0 livro Sugestões para um programa e o discurso de Pasqualini editado no livro com o manifesto da União Social Brasileira, ambos de 1945, são publicações relacionadas ao contexto de abertura política no fim do Estado Novo. Nesse mesmo contexto, Pasqualini publicou no jornal Correio do Povo boa parte de seus artigos, relativos à sucessão presidencial e ao caráter do processo que dava início a um novo regime político no país. Outro grande conjunto de artigos na imprensa situa-se entre 0 fim da campanha eleitoral de 1947 e a campanha eleitoral de 1950, período em que Pasqualini, mesmo sem mandato, consolidou sua inserção no PTB, sendo esses os artigos que, em sua maioria, tratam do trabalhismo e, entre 1949 e 1950, da candidatura de Vargas à presidência. Foi também nesse ínterim que Pasqualini lançou sua principal obra: Bases e sugestões para uma política social (1948).

A maior parte dos textos escritos por Pasqualini, contudo, são discursos e artigos reunidos posteriormente, como as coletâneas organizadas por Pedro Simon no Senado: Alberto Pasqualini: obra social e política - 4 volumes (Simon, 1994), Alberto Pasqualini textos escolhidos (Simon, 2001) e Atualidade de Alberto Pasqualini (Simon, 2010). Essas coletâneas, editadas a partir da década de 1980, foram tentativas de dar coesão a uma obra dispersa e marcada por contingências políticas diversas. Os quatro volumes organizados por Pedro Simon em 1994 são representativos do esforço de dar um encadeamento coerente aos textos de Pasqualini, incorrendo naquilo que destaca Diego Orgel Dal Bosco Almeida (2015: 24): a atuação anterior a 1945 aparece, em visão retrospectiva, como uma "espécie de preparação para seu posterior ingresso ao PTB". Como exemplo disso, o volume 1 da coletânea lançada em 1994, que abrange o período de 1929 a 1945, é nomeada de Bases do Trabalhismo, e os textos de 1944 e 1945 incluídos na seção intitulada Fundamentos da doutrina trabalhista ${ }^{8}$.

Ao se dividir os textos reunidos por Pedro Simon (1994), é possível perceber a origem distinta de cada um e o tipo de publicação que predomina em cada fase da trajetória de Pasqualini. Nota-se que os artigos, como referido anteriormente, concentram-se no período do Estado Novo — sendo a maior parte do ano de 1945 - e no interregno entre as campanhas eleitorais de 1947 e 1950. Este último período é também o de maior número de entrevistas, seguido da época em que exercia o mandato de senador. Quanto aos discursos, são em maior número provenientes do mandato de vereador (1936-1937) e de senador (1951-1955): seis no primeiro e nove no segundo. Além disso, 15 discursos foram proferidos no calor das campanhas eleitorais de 1934 (2), 1947 (4), 1950 (5) e 1954 (4). Percebe-se, portanto, o peso das disputas políticas e, especialmente, das campanhas eleitorais, no conjunto que foi classificado como obra social e política de Alberto Pasqualini. 


\title{
ANTES DO ESTADO NOVO, A PRIMEIRA APROXIMAÇÃO
}

\author{
atuação política de Alberto Pasqualini não se limitou ao trabalhismo, havendo uma trajetória \\ pregressa. Assim, o rótulo de teórico do trabalhismo não dá conta de compreendê-lo em
} perspectiva histórica, como afirmou Almeida (2015). 0 autor produziu uma tese sobre a atuação política de Alberto Pasqualini no Partido Libertador, especialmente no mandato de vereador em Porto Alegre (1936-1937), e no Estado Novo, analisando a forma como o protagonista utilizou os dividendos políticos advindos da atuação nesse período para sua inserção e consolidação como liderança no PTB após 1945. Assim, buscou compreender Pasqualini para além do teórico do trabalhismo, percebendo-o como detentor de um reconhecimento público advindo de sua atuação anterior a 1945, o que permitiu sua projeção política posterior como doutrinador e teórico do trabalhismo e a ressignificação de suas ideias a partir da adesão ao PTB (Almeida, 2015; 2019).

Apesar de Pasqualini ter tomado parte na chamada Revolução de $1930^{\circ}$, a relação direta com Getúlio Vargas somente teve início quando Pasqualini passou a exercer mandato de vereador em Porto Alegre e a galgar espaços na direção do Partido Libertador. Rafael Saraiva Lapuente (2017) estudou o processo de ruptura do acordo de pacificação política no Rio Grande do Sul, o chamado modus vivendi firmado por Flores da Cunha e seu Partido Republicano Liberal (PRL) com a oposição reunida na Frente Única Gaúcha (a FUG, composta do Partido Libertador e do Partido Republicano Rio-Grandense — PRR), abarcando o período de 1934 a 1937. Houve, por um lado, a crescente hostilidade até o rompimento final entre Flores da Cunha e Getúlio Vargas — às vésperas da decretação do Estado Novo - e, por outro, a aproximação entre Vargas e dissidentes da FUG (em que estava Alberto Pasqualini) e também do PRL (a dissidência liberal, em que estava Loureiro da Silva). Naquele contexto, a ação de Pasqualini se fez notar em, ao menos, três momentos-chave:

- No início de 1936, quando Vargas sondava os descontentes com o pacto entre Flores da Cunha e a oposição, Pasqualini, então vereador em Porto Alegre pelo $\mathrm{PL}$, aproximou-se de Vargas pela primeira vez ${ }^{10} \mathrm{e}$ atuou como um dos políticos que mantinham contatos entre dissidentes tanto da FUG quanto do PRL, informando o presidente sobre as "sondagens" acerca da implementação de um plano para a derrubada do acordo político no Rio Grande do Sul (Lapuente, 2017: 185-186). Lapuente (2017) cita uma carta de Pasqualini a Maurício Cardoso, liderança do PRR, e transcreve o plano (anexo à carta) sem autoria; sobre o plano, pode-se afirmar que se Pasqualini não foi o autor ou um dos autores, tinha pleno acordo sobre ele e empreendeu esforços para executá-lo. 0 plano está no arquivo do Centro de Pesquisa e Documentação de História Contemporânea do Brasil (CPDOC) 
(GV c1936.04.08/1). Pasqualini menciona o plano em carta enviada a Vargas em 11 de março de 1936: "[Maurício Cardoso] aprova o plano de ação esboçado no esquema do qual V. S. tem cópia"11;

- Na segunda metade de 1936, Pasqualini e Loureiro da Silva conversaram sobre a criação de um partido para congregar a dissidência liberal do PRL e a ala antiflorista da FUG, "caso não conseguissem ser maioria dentro de suas agremiações" (Lapuente, 2017: 245);

- Após um período de ataques da bancada antiflorista, liderada por Loureiro da Silva na Assembleia Legislativa do Rio Grande do Sul, Oswaldo Aranha retornou ao Brasil e tinha como uma de suas prioridades atenuar a crise política em seu estado natal, convencendo os dissidentes liberais a estabelecerem uma trégua até abril de 1937. Concomitantemente, Pasqualini iniciou uma série de entrevistas contra Flores da Cunha na imprensa do Rio de Janeiro, aumentando a crise. Conforme Lapuente, não é difícil perceber a jogada de Vargas, articulado com Pasqualini, ao permitir a publicação das entrevistas justamente quando Oswaldo Aranha tentava apaziguar a dissidência: "Não pode ser descartada a possibilidade de a atitude de Pasqualini ter sido calculada. Pois, caso ele tivesse feito as declarações na imprensa do Rio Grande do Sul, seria o governo estadual que teria o poder de permitir ou vetar" (Lapuente, 2017: 285).

Em suas conclusões, Lapuente (2017: 347) destaca os dividendos obtidos pelos políticos que se aproximaram de Vargas: "Tanto dissidentes quanto frenteunistas seriam recompensados por Getúlio Vargas pelas batalhas travadas contra o florismo. Eles obteriam a ocupação de cargos importantes dentro da política regional, com o rateio de secretarias, durante 0 Estado Novo". Carlos Cortés (2007: 151-152) afirma que, logo após a decretação do Estado Novo, Vargas encarregou seu irmão Benjamin e o libertador Batista Luzardo de institucionalizarem a aliança com os dissidentes do PL, PRR e PRL como "nova máquina política do governo". 0 que combina com a análise que Almeida (2015: 88) faz para o caso da participação de Alberto Pasqualini no Departamento Administrativo do Estado do Rio Grande do Sul e sua atuação à frente da Secretaria de Interior e Justiça: não eram os aspectos essencialmente técnicos que estavam em jogo na ocupação desses cargos, em que pese Pasqualini combinar sua liderança política a conhecimentos técnicos e administrativos. Conforme o autor, a passagem de Pasqualini por esses cargos entre 1939 e 1944 "rendeu-lhe alguns dividendos políticos vinculados ao gradual aumento de seu reconhecimento público, bem como de seus projetos e de suas ideias" (Almeida, 2015: 89). 
Ao buscar explicar o sucesso das principais lideranças políticas de uma geração anterior - como Getúlio Vargas, João Neves da Fontoura, Oswaldo Aranha, Maurício Cardoso, Lindolfo Collor e outros, a chamada "geração de 1907" — Grijó (1998) destaca aquilo que caracterizou tais trajetórias: o domínio de lógicas variadas (jurídica, burocrática, institucional, jornalística, dos combates militares) e a reconversão de recursos previamente detidos. Para 0 autor, isso também explica o sucesso de Maurício Cardoso e Lindolfo Collor, que não tinham origens sociais diretamente vinculadas ao mundo da estância, como Vargas, Aranha e outros, nem os recursos sociais dos grupos familiares dos demais, mas também puderam ascender politicamente "adquirindo recursos próprios ao investimento no jogo político como os de relações sociais e os culturais e escolares" (Grijó, 1998: 237). Grijó (1998) também destaca a importância de situações bem aproveitadas por esses políticos no início de suas trajetórias: a campanha eleitoral de 1907, para os casos de João Neves, Getúlio Vargas e outros, a militância política nas escolas superiores, como no caso de Oswaldo Aranha, a atividade na imprensa, no caso de Lindolfo Collor, uma bem-sucedida banca de advocacia e docência do direito no ensino superior, como no caso de Maurício Cardoso, constituíam vias de acesso aos círculos partidários e, no caso do PRR, "a oportunidade de mostrarem-se capazes de arcar com o peso das tarefas ou empreendimentos valorados como adequados e mesmo necessários para integração e aceitação no número destes partidários com possibilidades de obter cargos ou posições de destaque" (Grijó, 1998: 148).

Em relação a Alberto Pasqualini, também é possível considerar como pontos principais de sua trajetória aqueles que the permitiram adquirir recursos políticos e o domínio de lógicas variadas e reconvertidas em capital político: o seminário dos jesuítas, a atividade docente no Ginásio Anchieta, o curso na Faculdade de Direito, a atividade docente na mesma instituição, a banca de advocacia. Foi o contexto de desestabilização do governo Flores da Cunha e a aproximação da dissidência da Frente Única com Getúlio Vargas, especialmente entre 1936 e 1937, como abordado anteriormente, que forneceu a oportunidade bem aproveitada por Pasqualini de prestar serviços políticos a Vargas e consolidar sua posição como liderança política regional. Isso possibilitou a ocupação de cargos na estrutura estadual durante o Estado Novo e a aquisição de competências no plano administrativo, que somou à experiência legislativa como vereador.

\section{PASQUALINI E VARGAS: INTERPRETAÇÕES}

uando Miguel Bodea (1992) concebeu a formação do PTB do Rio Grande do Sul considerando três vertentes distintas (a sindicalista, a doutrinário-pasqualinista e a pragmático-getulista), estava referindo-se às origens distintas de cada um dos setores que seriam 
a base da construção do partido. Ao atentar para as trajetórias de lideranças como Alberto Pasqualini, José Vécchio ${ }^{12}$, Loureiro da Silva e José Diogo Brochado da Rocha e os conflitos entre elas, percebe-se as demarcações geradas pelos diferentes caminhos que as levaram ao convívio no PTB. 0 problema está na utilização dessas categorias como chaves explicativas para a compreensão da atuação dessas lideranças no partido. Tais categorias foram cristalizadas em seguida por Lucília de Almeida Neves Delgado (1989), para quem seriam duas as tendências atuantes no PTB: os getulistas ou pragmáticos, ligados especialmente ao Ministério do Trabalho, e os doutrinários ideológicos, entre os quais estava Alberto Pasqualini. Mais tarde, a autora inseriu no esquema os pragmáticos reformistas, que atuaram sobretudo a partir da metade dos anos 1950 e teriam amalgamado em sua prática características das duas alas anteriores. 0 expoente desse grupo seria João Goulart (Delgado, 2013: 178)13.

Uma crítica importante a essa abordagem surgiu na obra de Maria Celina D'Araújo (1996: 170): a dificuldade residiria em trabalhar com a clivagem ideológica versus o pragmatismo, como "se isso fosse um traço peculiar do PTB ou uma característica desviante da vida política". Para a autora, a luta interna que se travou no PTB acabou definindo sua ação política: "o nacionalismo no PTB não foi incompatível com o empreguismo, nem o reformismo foi antítese de clientelismo ou de atrelamento ao Estado. Ao contrário, foi bem-sucedido no partido e nas urnas quem conseguiu unir essas estratégias" (D'Araújo, 1996: 170). Recentemente, a dissertação de Maura Bombardelli (2016) sobre a trajetória de Fernando Ferrari no PTB apontou dificuldades de se compreender a inserção desse político no partido com base nas categorias utilizadas por Bodea (1992) e Delgado (1989). Isso levou a autora a discutir a dicotomia entre programáticos e pragmáticos: tais categorias estavam presentes no discurso político após 1954 e foram utilizadas como recurso para, no caso de Ferrari, se legitimar no enfrentamento contra João Goulart na luta interna do PTB (Bombardelli, 2016: 199).

Tais críticas reforçam a ideia de que houve absorção de categorias do discurso político por uma parte da historiografia, conformando uma interpretação acerca do PTB baseada na dicotomia entre os pragmáticos e os programáticos (ou doutrinários), simbolizada nos conflitos entre João Goulart e Fernando Ferrari, a partir da metade da década de 1950, e antes, nos conflitos entre Getúlio Vargas e Alberto Pasqualini. Com isso, no vocabulário dos estudos sobre o trabalhismo, com algumas exceções, Vargas tornou-se sinônimo de pragmático e Pasqualini sinônimo de doutrinário.

A tese defendida por Silva (2012) teve como foco a trajetória política de Alberto Pasqualini. 0 autor insere a atuação de Pasqualini no contexto de controvérsias e tensões no PTB, acompanhando a sua atuação política no meio partidário e no Senado Federal (1951-1955). Silva (2012: 54) salienta o papel doutrinador de Pasqualini, destacando a posição central 
desempenhada pelo político gaúcho nas atividades doutrinárias na fase de formação e estruturação do PTB. 0 autor atribui importância acentuada ao conflito existente entre o pragmatismo getulista e o idealismo pasqualinista. Assim, Silva (2012) diferencia-se da abordagem defendida por Bodea (1992), para quem houve uma divisão de tarefas na qual Getúlio Vargas desempenharia um papel no âmbito do Estado e Alberto Pasqualini no da sociedade civil. Conforme Bodea (1992: 140), a dimensão essencial do relacionamento entre Vargas e Pasqualini não se situa no confronto entre duas tendências políticas distintas ou rivais, mas na dinâmica dessa divisão de tarefas, como mencionado anteriormente.

Laura Vasconcellos (2009) retomou, em sua dissertação sobre o trabalhismo de Pasqualini, os argumentos de Miguel Bodea. Para a autora, Pasqualini sempre se mostrou mais idealista do que Vargas no tema das alianças políticas, pois, mesmo carecendo de apoio nas eleições, ele hesitava em receber e dar apoio a partidos ou a políticos que não estivessem em consonância com os ideais trabalhistas, enquanto o ex-presidente, ao contrário, era mais pragmático (Vasconcellos, 2009: 76). Contudo, a autora busca dar conta, em certa medida, da prática política de Pasqualini: "Sua memória e seu discurso de homem puro e idealista contrastam com uma prática política que em muito pouco destoava da maneira como Vargas concebia a política e a história do Brasil" (Vasconcellos, 2009: 70). A autora conclui:

Apesar de ressaltar toda a elaboração doutrinária e teórica de Pasqualini, e de destacar a sua peleja em transformar o PTB num partido com maior densidade teórica, não podemos deixar de esclarecer também [...] que Pasqualini, apesar de todo o discurso e querelas com Vargas, foi homem de confiança de Getúlio e do PTB. Grande parte de suas colocações e questionamentos jamais deixou de ser meramente figura de retórica, sem jamais se traduzir numa prática política efetiva. (Vasconcellos, 2009: 99)

Haveria então uma relação harmônica e combinada entre suas ações? Há motivos para também não aceitar esse argumento, levando à necessidade de compreender essa relação em sua complexidade e as circunstâncias que propiciaram que os caminhos de Vargas e Pasqualini se cruzassem em diferentes momentos. Miguel Bodea, ao defender a ideia de divisão de tarefas entre Vargas e Pasqualini, trouxe alguns indicativos importantes que, embora possam resultar, nesse momento, em prejuízos ao argumento de Bodea, demonstram como as relações entre ambos, com seus recuos e aproximações, dão-se em diferentes momentos e concernem a objetivos circunstanciais - e assim colaboram com o argumento defendido no presente artigo. Destacam-se alguns momentos da relação Vargas-Pasqualini observados por Bodea (1992: 165-168):

- $\quad$ Na fase de acordo entre a União Social Brasileira (USB) e o PTB, em 1945, 0 conflito deu-se quando Pasqualini e as lideranças sindicais do PTB não aceitaram 
apoiar a candidatura de Eurico Dutra (PSD) conforme a orientação de Vargas. Na sequência, o PTB não seguiu a orientação de Vargas de constituir uma aliança com o PSD para as eleições estaduais de 1947;

- Na campanha eleitoral de 1946/1947, houve uma "desconfiança mútua", pois Vargas apoiou Pasqualini como candidato a governador pelo PTB, mas se dedicou pouco à campanha no Rio Grande do Sul, buscando manter a ruptura com o PSD apenas no âmbito regional. Por sua vez, Pasqualini evitou referências a Getúlio em seus pronunciamentos;

- Na campanha de 1950, Pasqualini, candidato a senador, assumiu a defesa de Vargas, havendo "pleno entrosamento" entre ambos, em uma fase em que "Getúlio privilegia o PTB como instrumento básico de seu retorno ao poder" (Bodea, 1992: 160);

- Após a vitória em 1950, Vargas buscou recompor a aliança com o PSD e sua base de sustentação nas elites. Nesse momento, Pasqualini e grande parte dos trabalhistas gaúchos estavam insatisfeitos com o governo e, especialmente, com a pouca participação do PTB. Pasqualini fez até mesmo pronunciamentos críticos ao governo na tribuna do Senado;

- No momento de confronto crescente com a oposição, entre 1953 e 1954, coincidindo com a nomeação e posterior demissão de João Goulart no Ministério do Trabalho, ocorreu uma reaproximação de Pasqualini com Vargas - que o apoiou como candidato a governador em 1954 em detrimento dos demais postulantes "mais pragmáticos e moderados"14.

Deixando de lado a dicotomia dos rótulos pragmático e doutrinário, e recorrendo a algumas fontes, é possível perceber a relação entre Vargas e Pasqualini de forma mais aprofundada. Como exemplo, tem-se a posição de Pasqualini com relação à candidatura de Getúlio Vargas em 1950.

\section{PASQUALINI, VARGAS E AS ELEIÇÕES DE 1950}

$\mathrm{E}$ 29 de dezembro de 1949, o Correio do Povo reproduziu entrevista concedida por Alberto Pasqualini à Folha Carioca. Nela, o comentarista político do periódico ressaltou que Pasqualini liderava, no PTB, "a corrente ideológica que se bate pela formação de uma verdadeira consciência, de um programa, e não pela mística transitória de um chefe". Assim, após um período intenso de pregação do trabalhismo por meio de artigos e entrevistas, iniciado depois da campanha eleitoral de 1947, a imprensa já traçava um perfil de Pasqualini 
operando com a categoria teórico do trabalhismo, como fica claro no seguinte excerto: "Pasqualini não pertence ao número dos que veem no PTB apenas a sombra protetora, patriarcal e eleitoral de Vargas. [...] Pasqualini é o teórico-filósofo do trabalhismo brasileiro". Segundo a matéria da Folha Carioca, Pasqualini defendia que, caso se lançasse a candidatura de Getúlio Vargas à presidência, seria necessário um pacto entre o PTB e o Brigadeiro para garantir a realização das eleições. 0 redator concluiu: "Pasqualini não é dos que acham que não há mais clima para golpe no Brasil. Ele sabe que ele poderia ser criado. Daí a ideia no sentido de que dos entendimentos atuais resulte uma garantia da realização das eleições no dia fixado" 15 .

No mês seguinte, Ivete Vargas ${ }^{16}$ enviou carta ao seu tio-avô Getúlio com um recado de Pasqualini: "Acha que o senhor deve se candidatar, mas deve correr o mínimo de risco. Portanto deve se tratar da organização do partido, da propaganda doutrinária e deve se fazer uma campanha superior sem ataques pessoais e sem demagogia"17. Ivete Vargas também informou a Getúlio sobre a conversa de Pasqualini com o deputado Prado Kelly, da União Democrática Nacional (UDN): "Tem conversado muito com o Prado Kelly e ambos convêm que não se deve fazer ataques ao que passou. A UDN fará uma campanha cordial em relação a nós, sem alusão à ditadura ou ao que passou". E concluiu o recado de Pasqualini, que achava imprescindível que Getúlio desse instruções nesse sentido aos companheiros, retomando os argumentos defendidos na entrevista à Folha Carioca: "Assim agindo seremos duas forças paralelas defendendo a legalidade. Caso contrário, nos estraçalharemos criando ambiente para o golpe" 18 .

Curiosamente, há anotações de Getúlio Vargas destinadas ao presidente nacional do PTB, Salgado Filho, em maio daquele ano, com recomendações para um entendimento com a UDN sobre o tipo de campanha política a ser executada por ambos os partidos: "Combinar com a UDN, enquanto partido de oposição, fazer com o PTB uma campanha política de cordialidade, sem ataques pessoais, nem referências ao passado". As anotações de Getúlio expressam exatamente o que havia sido recomendado por Pasqualini, prevendo dar instruções aos petebistas para que a campanha se procedesse assim. E repete 0 argumento presente na entrevista de Pasqualini e na carta de Ivete Vargas: "Seremos duas forças paralelas agindo serenamente, no sentido de oposição ao candidato do Catete" ${ }^{19}$. Getúlio não detinha o monopólio das estratégias políticas, tampouco Pasqualini tinha sua ação circunscrita ao aspecto programático.

Pouco tempo antes das anotações referidas, porém, outra carta de Ivete Vargas revelou divergência entre os interesses de Getúlio e de Pasqualini. Ivete não havia, até então, convivido muito com seu tio-avô, mas atuava politicamente desde a campanha de Dutra, em 1945, a pedido de Getúlio. No início de 1950, passou uma temporada na fazenda de Itu, em 
São Borja. Na carta de 30 de abril, fez a seguinte observação: "A minha estadia aí anulou todo um longo trabalho de Pasqualini, que me doutrinara durante meses. Voltei novamente queremista apenas e mandando o trabalhismo, com toda a sua filosofia política, plantar favas" 20 .

Os meses se seguiram e a candidatura de Vargas foi se consolidando. Em carta enviada ao "prezado amigo" Getúlio, em 8 de julho de 1950, Pasqualini ressaltou a necessidade de se fixar claramente quais eram os objetivos do trabalhismo, para evitar explorações e deturpações quando a campanha eleitoral atingisse maior intensidade. Dizia Pasqualini: "Se a campanha eleitoral for colocada apenas em termos de prestígio pessoal, um eventual insucesso poderia ser um desastre. Se, porém, o senhor for o líder de uma orientação social, de uma ideia $[$, ... a perda de uma eleição em nada poderia abalar o seu prestígio". Pasqualini segue em suas sugestões a Vargas:

Ao senhor, particularmente, creio que não conviria, por maiores que sejam as probabilidades de triunfo, apostar e arriscar tudo nesta parada. Uma vitória política nem sempre se traduz por uma expressão eleitoral, numa contagem material de votos, e, muitas vezes, não valeria a pena consegui-la com o sacrifício daquilo que deve ser o objetivo dessa vitória. Veja, apenas, Presidente, nestas palavras o reflexo da intenção sincera de quem deseja seu nome cada vez mais engrandecido, mas, ao mesmo tempo, resguardado de eventualidades e surpresas que uma política primária, como a que se pratica em nosso país, pode preparar (grifos do autor) ${ }^{21}$.

A resposta de Getúlio aparece em carta remetida à sua filha Alzira Vargas em 14 de julho, na qual menciona haver incumbido Manuel Vargas de transmitir pessoalmente sua resposta a Pasqualini: "Eu não vou fazer campanha doutrinária de trabalhismo e sim um programa objetivo de administração. Campanha para vencer, com aliados que não são do partido e com o povo em geral". Apesar disso, a resposta de Getúlio a Pasqualini oferecia uma perspectiva em caso de vitória: "Se vencer, Pasqualini será incumbido de rever o programa do PTB e de reorganizá-lo sob as bases programáticas" 22 .

Ivete Vargas havia incentivado a aproximação de Getúlio com Pasqualini. Em uma das missivas, a seguinte observação chama a atenção: "O Pasqualini tem uma vontade imensa de ser seu representante pessoal na convenção, caso o senhor não venha. Ele me disse que iria a Itu para o senhor dar os rumos do discurso e ele faria o discurso, acrescentando o sal e a pimenta necessários" 23 . Getúlio Vargas não compareceu à convenção nacional do PTB, mas seu discurso foi irradiado diretamente de São Borja e sua voz pôde ser ouvida nas caixas de som instaladas no Palácio Tiradentes, no Rio de Janeiro — então capital federal. Na ocasião, Alberto Pasqualini discursou aos convencionais: 
Estamos agora na segunda etapa do trabalhismo. A legislação social do governo do presidente Getúlio Vargas outorgou as garantias jurídicas ao trabalhador, a sua carta de alforria. [...] Vamos agora iniciar a segunda fase que é dar maior amplitude à legislação social, estendendo seus benefícios, sobretudo os da previdência social, a todos os trabalhadores. [...] Getúlio Vargas é novamente chamado para realizar essa segunda etapa [...]. Sua candidatura não tem, portanto, um sentido negativo e demagógico; não é dirigida contra ninguém, não tem os olhos voltados para o passado, porque nos interessa apenas o futuro ${ }^{24}$.

Em 10 de agosto de 1950, a executiva estadual do PTB do Rio Grande do Sul, sob a presidência de João Goulart, definiu o nome de Alberto Pasqualini como candidato ao Senado, indicado por Getúlio Vargas. Como candidato ao Senado, Pasqualini teve mais uma vez sua imagem pública associada à de Getúlio Vargas e avançou ainda mais na defesa de Vargas, ao contrário da postura assumida por ele mesmo na campanha anterior. Como nos indicou o comentário de Ivete Vargas sobre ser queremista, o "queremismo" dessa vez se concretizava em uma candidatura de Vargas sob a sigla do PTB. Sobre isso, Pasqualini afirmou em discurso na campanha eleitoral: "O queremismo é o trabalhismo representado e explicado através de uma figura humana; o trabalhismo é o queremismo na sua expressão racional. [...] 0 queremismo é a fé. 0 trabalhismo é a razão. Mas, a razão e a fé não se excluem, antes se completam" 25 .

\section{CONSIDERAÇÕES FINAIS}

o seu conjunto, as relações políticas entre Getúlio Vargas e Alberto Pasqualini foram
interpretadas de maneiras distintas. Em uma vertente, haveria uma dicotomia entre ambos, baseada em modi operandi distintos e antagônicos, relativos ao caráter pragmático do primeiro e doutrinário/programático do segundo. Em outra, as ações de ambos se combinariam não de modo antagônico, mas gerando uma complementaridade - embora conflitiva, segundo Miguel Bodea - em que o aspecto doutrinário de Pasqualini legitimaria o partido liderado pragmaticamente por Vargas. Um caminho alternativo consiste em não aceitar totalmente a ideia da complementaridade conflitiva proposta por Bodea, em razão da divisão de tarefas que relega a Pasqualini o papel monocórdico de doutrinador e a Vargas o monopólio da estratégia política.

Com base nesse exemplo da atuação de Alberto Pasqualini na candidatura de Getúlio Vargas em 1950, foi possível retomar e considerar um dos aspectos presentes na noção de divisão de tarefas proposta por Miguel Bodea: a complementaridade conflitiva entre o projeto político nacional de Vargas e o projeto de construção do PTB por Pasqualini. Diferentemente de Vargas, que possuía uma estratégia dual de articulação política (envolvendo PSD e PTB), Pasqualini teve no PTB seu instrumento fundamental de implementação de reformas sociais a 
partir de 1946 (Bodea, 1992: 152). Essa tensão esteve presente na candidatura de Vargas em 1950 e no modo como Pasqualini se inseriu no apoio a ela.

As fontes analisadas impõem limites ao caminho que aposta no antagonismo entre Vargas e Pasqualini e na dicotomia entre as práticas de ambos. É possível perceber que, indo além da simples dicotomia entre pragmáticos-getulistas e programáticos-pasqualinistas, a relação entre Vargas e Pasqualini se dá em um complexo processo de recuos e aproximações e em alianças afetadas pelas contingências e que não dizem respeito somente às estratégias de Vargas, mas ao próprio projeto político de Pasqualini e aos seus objetivos circunstanciais com relação ao jogo político. Desde o momento inicial da relação entre ambos, é possível perceber esse movimento pelo qual se coadunam os objetivos em comum e os interesses próprios de cada um.

\section{NOTAS}

1 Recentemente, dissertações e teses defendidas no âmbito da pós-graduação em história em instituições do Rio Grande do Sul revigoraram o debate sobre o trabalhismo. Essas contribuições estão sintetizadas especialmente na obra organizada por Carla Brandalise e Marluza Harres (2017).

2 José Loureiro da Silva (1902-1964) foi prefeito de Porto Alegre durante o Estado Novo e ingressou no PTB em 1946, liderando a migração de políticos oriundos do Partido Social Democrático (PSD) para a sigla trabalhista no Rio Grande do Sul.

3 José Diogo Brochado da Rocha (1904-1981) foi militar e diretor da Viação Férrea do Rio Grande do Sul durante o Estado Novo, eleito deputado federal pelo PSD em 1945, migrou para o PTB, sendo eleito deputado estadual em 1947 e deputado federal em 1950.

4 Pasqualini era filiado ao Partido Libertador, que formava Frente Única com o Partido Republicano Rio-Grandense (PRR) desde 1928. Após a Revolução Constitucionalista de 1932, que contou com a adesão de grande parte da Frente Única, o interventor Flores da Cunha fundou o Partido Republicano Liberal (PRL). À medida que se acentuava a dissenção entre Flores da Cunha e Getúlio Vargas, este último estabelecia contatos com lideranças da Frente Única Gaúcha (FUG) visando a uma aliança e ao enfraquecimento de Flores, incentivando a atuação de Pasqualini, pelo lado do Partido Libertador, e de Loureiro da Silva, pelo lado da dissidência liberal (no PRL), ambos em forte oposição ao governo estadual (Cortés, 2007: 122-128; Grijó, 2007: 89).

5 Os termos estão grifados para destacar a origem conceitual da interpretação de Bodea, que se embasa na leitura do teórico italiano Antonio Gramsci (1891-1937). Em obra que Bodea 
menciona, Gramsci (1968) concebe a luta política indo além dos interesses de classe: embora cada partido seja expressão de determinado grupo social, admite-se a possibilidade de 0 partido exercer uma função de arbitragem entre os interesses do grupo e de outros grupos.

6 Miguel Bodea (1948-1988) formou-se em economia por Cambridge e era mestre em ciência política pela Universidade de São Paulo (USP), com a dissertação, publicada em 1992, Trabalhismo e populismo no Rio Grande do Sul. Foi assessor parlamentar do MDB na Assembleia Legislativa do Rio Grande do Sul na década de 1970 e assessor de Leonel Brizola no Rio de Janeiro na década de 1980 (Grill, 2008: 198-199).

70 embasamento está nas formulações de Norberto Bobbio sobre os tipos de intelectuais, inclusive quanto à obediência a éticas diferentes (com origem na discussão weberiana): os ideólogos seguindo a ética da convicção - fiéis a certos princípios a qualquer custo - e os expertos seguindo a ética da responsabilidade — tendo o dever de levar em conta os meios adequados e suas consequências (Bobbio, 1997: 76).

8 É importante ressaltar que Alberto Pasqualini somente ingressou no PTB em 1946. Nos discursos, artigos e entrevistas anteriores a 1946, não há referências ao trabalhismo, havendo, até mesmo, um distanciamento com relação a Getúlio Vargas (Bodea, 1992: 26; Silva, 2012: 102; Almeida, 2015: 109).

9 Foi major fiscal do $11^{\circ}$ batalhão provisório "João Pessoa" no cais do porto de Porto Alegre. Acervo de Alberto Pasqualini - Prefeitura Municipal de Ivorá/RS (AAP-PMI). Pasta 01.

100 primeiro volume do Diário de Getúlio Vargas (1995: 472) menciona Pasqualini pela primeira vez entre 24 e 26 de janeiro de 1936: "Recebi, uma noite, à insistência de Lulu Aranha [Luís Aranha, irmão de Oswaldo Aranha], o Pasqualini, com quem conversei longamente sobre o acordo do Sul".

11 CPDOC GV c1936.04.08/1. AAP-PMI- Pasta 27.2.

12 José Vecchio (1909-1994) foi um líder sindical e um dos fundadores do PTB no Rio Grande do Sul.

13 Delgado menciona Gláucio Soares (1973), para quem haveria três facções distintas no PTB: os sindicalistas pelegos, os doutrinários e os pragmáticos-getulistas. A autora entende, no entanto, que os grupos eram apenas dois, tendo em vista que "os sindicalistas pelegos eram também pragmáticos-getulistas" (Delgado, 1989: 59).

14 Loureiro da Silva e José Diogo Brochado da Rocha (Bodea, 1992: 168).

150 SR. ALBERTO Pasqualini e os problemas brasileiros. Correio do Povo, Porto Alegre, 29 dez. 1949, p. 14. 
16 Cândida Ivete Vargas Tatsch (1927-1984) era sobrinha-neta de Getúlio Vargas, intelectual e jornalista, ingressou no PTB em 1945, sendo eleita deputada federal em 1950.

17 A carta consta no sistema de buscas do CPDOC como "sem assinatura". Comparação com outras cartas permite identificar Ivete Vargas, sobrinha-neta de Getúlio, como remetente. 18 CPDOC-FGV. GV c 1950.01.00/5. Carta sem assinatura contendo recomendações de Alberto Pasqualini para Getúlio Vargas. Jan. 1950.

19 CPDOC-FGV. GV c 1950.05.00/3. Notas políticas de Getúlio Vargas para Salgado Filho. Maio 1950.

20 CPDOC-FGV. GV c 1950.04.30. Carta de Ivete Vargas a Getúlio Vargas. 30 abr. 1950.

21 CPDOC-FGV. GV c 1950.07.08. Carta de Alberto Pasqualini a Getúlio Vargas. 08 jul. 1950.

22 CPDOC-FGV. AVAP vpu e 1946.01.02. Carta de Getúlio Vargas à Alzira Vargas do Amaral Peixoto. 14 jul. 1950.

23 CPDOC-FGV. GV c 1950.07.00/3. Carta de Ivete Vargas a Getúlio Vargas. Jun. 1950.

24 AFIRMA o Sr. Alberto Pasqualini que a candidatura Vargas não é dirigida contra ninguém e nem constitui um desafio. Correio do Povo, Porto Alegre, 18 jun. 1950, p. 32.

25 A VOCAÇÃO política do Rio Grande. Importante conferência do Sr. Alberto Pasqualini no Cine-Teatro Glória em Alegrete. Correio do Povo, Porto Alegre, 10 set. 1950, p. 10.

\section{REFERÊNCIAS BIBLIOGRÁFICAS}

ALMEIDA, D. O. D. B. Interfaces do político: o discurso de Alberto Pasqualini em perspectiva (1936-1955). Tese (Doutorado em História) - Pontifícia Universidade Católica do Rio Grande do Sul, Porto Alegre, 2015.

ALMEIDA, D. O. D. B. A trajetória de Alberto Pasqualini antes do 'teórico do trabalhismo': background, entrada e estratégias de ascensão na política-partidária (1928-1937). História: Debates e Tendências, Passo Fundo, v. 19, p. 636-658, 2019. https://doi.org/10.5335/hdtv.19n.4.10490.

BOBBIO, N. Os intelectuais e o poder. São Paulo: UNESP, 1997.

BODEA, M. Trabalhismo e populismo no Rio Grande do Sul. Porto Alegre: UFRGS, 1992.

BOMBARDELLI, M. A trajetória de Fernando Ferrari no PTB: da Formação do Partido ao "Trabalhismo Renovador" (1945-1960). Dissertação (Mestrado em História) - Universidade Federal do Rio Grande do Sul, Porto Alegre, 2016.

BRANDALISE, C.; HARRES, M. M. (orgs.). O PTB do Rio Grande do Sul e a experiência democrática (19451964). São Leopoldo: Oikos, 2017. (Coleção Ehila v. 34).

CORTÉS, C. E. Política Gaúcha (1930-1964). Porto Alegre: EDIPUCRS, 2007.

D'ARAÚJO, M. C. Sindicatos, carisma e poder: o PTB de 1945-1965. Rio de Janeiro: FGV, 1996. 
DELGADO, L. A. N. PTB, do getulismo ao reformismo (1945-1964). São Paulo: Marco Zero, 1989.

DELGADO, L. A. N. Trabalhismo, nacionalismo e desenvolvimentismo: um projeto para o Brasil. In: FERREIRA, J. (org.). O populismo e sua história: debate e crítica. Rio de Janeiro: Civilização Brasileira, 2013. p. 167-203.

GRAMSCI, A. Maquiavel, a política e o Estado Moderno. Rio de Janeiro: Civilização Brasileira, 1968.

GRIJÓ, L. A. Origens sociais, estratégias de ascensão e recursos dos componentes da chamada "geração de 1907". Dissertação (Mestrado em Ciência Política) - Universidade Federal do Rio Grande do Sul, Porto Alegre, 1998.

GRIJÓ, L. A. Alberto Pasqualini: o teórico do trabalhismo. In: FERREIRA, J.; REIS, D. A. (org.). As esquerdas no Brasil. v. 2. Rio de Janeiro: Civilização Brasileira, 2007. p. 83-99.

GRILL, I. G. "Heranças políticas" no Rio Grande do Sul. São Luís: EDUFMA, 2008.

LAPUENTE, R. S. Com a espada de Dâmocles: o Rio Grande do Sul e a política brasileira no governo Flores da Cunha. Curitiba: Prismas, 2017.

PASQUALINI, A. Bases e sugestões para uma política social. Porto Alegre: Editora do Globo, 1948.

SILVA, R. B. Alberto Pasqualini: trajetória política e pensamento trabalhista. Niterói: UFF, 2012.

SIMON, P. (org.). Alberto Pasqualini: obra social e política. v. 4. Brasília: Senado Federal, 1994.

SIMON, P. (org.). Alberto Pasqualini: textos escolhidos. Brasília: Senado Federal, 2001.

SIMON, P. (org.). Atualidade de Pasqualini. Brasília: Senado Federal, 2010.

SOARES, G. A. D. Sociedade e política no Brasil (Desenvolvimento, classe e política durante a Segunda República). São Paulo: Difusão Europeia do Livro, 1973.

VARGAS, G. Diário. v. 1. Rio de Janeiro: FGV, 1995.

VASCONCELLOS, L. V. Alberto Pasqualini e o trabalhismo no Brasil. Dissertação (Mestrado em História) Universidade Estadual do Rio de Janeiro, Rio de Janeiro, 2009.

WEBER, M. Ciência e política: duas vocações. São Paulo: Cultrix, 2011. 